Int. J. Electrochem. Sci., 12 (2017) 8295 - 8305

\title{
Effects of ZnO Sintering Additive on the Sintering Behavior and Conductivity of YSZ Solid Electrolyte
}

\author{
Fang Yang ${ }^{1}$, Hao Fang ${ }^{1}$, Qian Hu ${ }^{1}$, Chunjun Zhao ${ }^{1}$, Xiuzhen Qian ${ }^{1}$, Chunhua Zhao, ${ }^{1, *}$ \\ ${ }^{1}$ Key Laboratory for Ultrafine Materials of Ministry of Education, School of Materials Science and \\ Engineering, East China University of Science and Technology, Shanghai 200237, China \\ *E-mail: zhaochh@ecust.edu.cn
}

doi: $10.20964 / 2017.09 .21$

Received: 8 June 2017 / Accepted: 4 July 2017 / Published: 13 August 2017

The effects of $\mathrm{ZnO}$ sintering additive on the sintering behavior and electrochemical properties of YSZbased solid electrolyte were investigated. With the addition of $3 \mathrm{~mol} \% \mathrm{ZnO}$, the linear shrinkages of YSZ at $1200{ }^{\circ} \mathrm{C}$ increased from $7.1 \%$ to $15 \%$, and the relative density at $1200^{\circ} \mathrm{C}$ increased from $82 \%$ to $94.6 \%$. XRD confirmed that a small amount of $\mathrm{Zn}$ can be incorporated into the fluorite lattice, and EDX result showed that $\mathrm{ZnO}$ mainly distributed at the grain boundary. $\mathrm{ZnO}$ modified YSZ had denser structure and fewer pores than YSZ. The increased densification of YSZ by ZnO addition can significantly increase the grain and total conductivities. Compared with YSZ, the total conductivity of $2 \mathrm{~mol} \% \mathrm{ZnO}$ modified YSZ increased from 0.013 to $0.021 \mathrm{~S} \cdot \mathrm{cm}^{-1}$ at $800{ }^{\circ} \mathrm{C}$.

Keywords: ZnO modified YSZ; Sintering property; Electrochemical property; Solid oxide electrolyte

\section{FULL TEXT}

(C) 2017 The Authors. Published by ESG (www.electrochemsci.org). This article is an open access article distributed under the terms and conditions of the Creative Commons Attribution license (http://creativecommons.org/licenses/by/4.0/). 